\title{
Joint Transport Research Centre
}

ROUND TABLE

4-5 February 2010, Paris

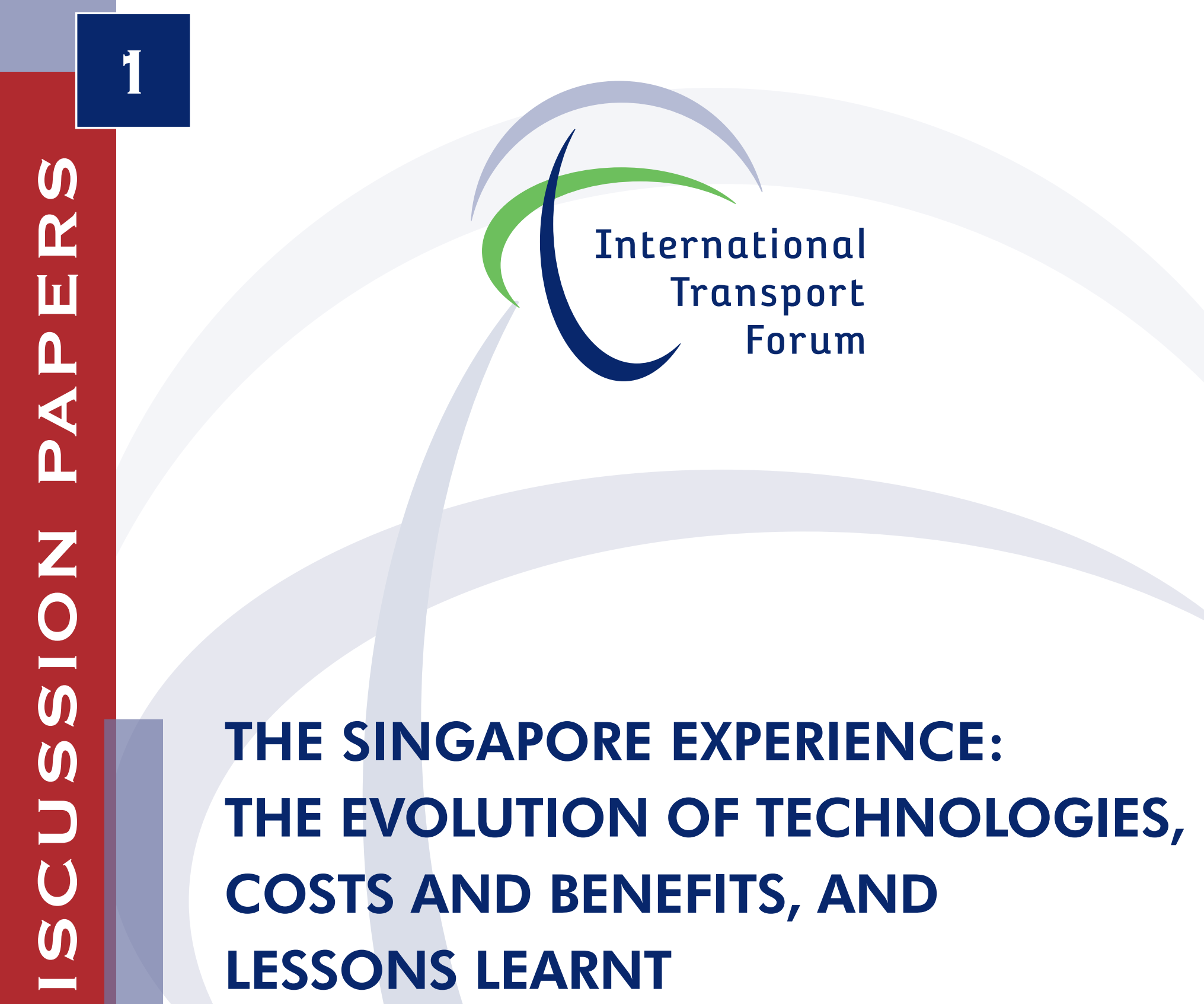


Discussion Paper No. 2010-1

Prepared for the ITF/OECD Round Table of 4-5 February 2010 on Implementing Congestion Charging

The Singapore experience: The evolution of technologies, costs and benefits, and lessons learnt

\section{Kian-Keong CHIN}

Land Transport Authority

Road Operations \& Community Partners

Singapore

Malaysia

December 2009

The views expressed in this paper are the author's, and do not necessarily represent the opinions of the Singapore Land Transport Authority, the International Transport Forum or the OECD. 


\section{THE SINGAPORE EXPERIENCE: THE EVOLUTION OF TECHNOLOGIES, COSTS AND BENEFITS, AND LESSONS LEARNT}

\section{INTRODUCTION}

Singapore is an island-state with a land area of about 710 square $\mathrm{km}$, measuring $42 \mathrm{~km}$ across and $23 \mathrm{~km}$ from north to south. Densely populated with more than 4.8 million people, its transport needs are served by an infrastructure of $147 \mathrm{~km}$ of MRT/LRT ${ }^{1}$ lines and 3,300 $\mathrm{km}$ of roads catering to more than 900,000 vehicles.

Given its land constraints, Singapore's overall transportation strategy cannot rely on building roads and more roads to serve its populace's travel needs. It needs a comprehensive and affordable public transport system and sustainable demand management tools. Hence, its recently launched Land Transport MasterPlan is based on making public transport a choice mode, while continuing to manage road usage and to meet the diverse needs of its travelers. A key element to meet these objectives is the continued use of road pricing.

Road pricing has long been associated with Singapore, starting way back in June 1975 . Many changes have been made to the road pricing scheme since that time. Started as a manual scheme based on paper permits and hence, using little technology, it has evolved to become a sophisticated system today, involving various technologies. The economic principles for road pricing however, continues to be valid but the charging structure had been evolving to keep the scheme effective, and deriving benefits to the community as a whole.

\section{MANUAL ROAD PRICING SCHEME}

The manual scheme, called the Area Licensing Scheme (ALS), was based on the display of paper licenses that were purchased prior to their entering the part of city defined as the Restricted Zone (RZ). This scheme was in operation for 23 years before it was replaced with the Electronic Road Pricing System (ERP) in 1998.

1. Mass Rapid Transit/Light Rapid Transit. 
To enter the RZ during the restriction periods, non-exempt vehicles needed to purchase an ALS area licence from roadside sales booths located on approach roads to the RZ, petrol stations, post offices or convenience stores. These are available as daily and monthly ALS area licences.

Enforcement personnel were stationed at the control points to ensure that non-exempt vehicles displayed valid ALS area licences on their windscreens, or on the handle-bars in the case of motorcycles and scooters. Violating vehicles had their vehicle licence numbers noted down and their owners sent summonses for entering the $R Z$ without a valid licence. Vehicles were free to move around or leave the $R Z$ without having the ALS area licences.

\section{Operating Hours}

The ALS started in June 1975 with the restricted hours of 7.30am - 9.30am daily, except on Sundays and public holidays. Three weeks later, the restricted hours were extended to $10.15 \mathrm{am}$ in order to restrain the surge in vehicle entries immediately after the lifting of the ALS at 9:30am. The ALS operated for $23 / 4$ hours each weekday during the morning peak period until June 1989, when fundamental changes were made. The restriction period was extended to cover the evening peak hours of $4.30 \mathrm{pm}$ to $7.00 \mathrm{pm}$ on weekdays.

In Jan 1994, more fundamental changes were made to the ALS scheme. The restricted hours were further extended to cover the 10.15am - 4.30pm time period on weekdays and the post-peak morning period of $10.15 \mathrm{am}-3.00 \mathrm{pm}$ on Saturdays. The Saturday restriction period was subsequently cut back to $2.00 \mathrm{pm}$ due to improved traffic conditions within the $R Z$.

\section{AFFECTED VEHICLES AND CHARGES}

When the ALS started in 1975, taxis, public transport buses, goods vehicles, motorcycles, and passenger cars carrying three or more passengers (car-pooling) were exempted from the scheme. A few months later, in August of the same year, the exemption on taxis was removed.

In June 1989, motorcycles and good vehicles were also required to purchase ALS licences prior to their entering the $\mathrm{RZ}$ during the restriction period. Exemptions for car-pools were also removed because private cars were picking up bus commuters instead of forming genuine car-pool.

Starting at $\$ 3^{2}$ per day for an ALS licence for cars in 1975 , this crept up to $\$ 5$ per day in 1980. However, with the major review in 1989, there was a reduction in rates because more vehicles were then required to purchase licences. The daily licence fee for a car was reduced back to $\$ 3$.

2. The fees mentioned in this paper are in Singapore \$, and as at December 2009, the exchange rate is US $\$ 1=\mathrm{S} \$ 1.40$. 
The Jan 1994 changes also saw two levels of fees for two different types of licences - the one that allows usage throughout the day, and the one for use during the inter-peak period only. The fees were $\$ 3$ and $\$ 2$ respectively for cars.

\section{TRAFFIC IMPACT}

Traffic entering the $R Z$ dropped by $44 \%$ initially but it went up to a $31 \%$ drop by 1988 . However, this was despite the growth by a third in employment in the city and by $77 \%$ in vehicle population during the same period. The drop in traffic arose from the decanting of motorists whose destinations were not in the city but had been using the city roads as a bypass, as well as by those who entered the city earlier to avoid having to buy ALS area licences.

\section{GOING FROM MANUAL TO ELECTRONIC}

Being manually operated, the ALS required substantial manpower. About 60 enforcement personnel and another 60 officers at dedicated licence sales booths were required each day. The enforcement duties were demanding, given the long hours spent under the sun and rain, not to mention the dust and the noise. In addition, there were 16 different types of licences in use at its peak, and much concentration by the enforcement officers was required to ensure that they identified them correctly. It was inevitable that there were errors made sometimes, resulting in the occasional wrongful issue of summonses.

There was always a rush to enter the $R Z$ just before or after the restricted hours because of the significant change of licence fee from nothing to $\$ 3$ or vice versa. This resulted in sharp and short peaks in traffic volume entering the city. Having intermediate or shoulder rates would have smoothened out the peaks, but it was difficult to implement given the need for more types of paper licences that have to be distinguished by enforcement officers.

\section{ELECTRONIC ROAD PRICING (ERP)}

With the shortcomings of the manual road pricing scheme, the search for a more efficient technology began in earnest in the early 1990s. Technology for an electronic road tolling system was emerging at that time, and after several years of prototype testing with potential 
suppliers $^{3}$, a contract for the installation of a Dedicated Short-Range Communication (DSRC) electronic road pricing system was awarded in 1995.

The ERP system has three major groups of components. The first centred around the invehicle Unit (IU) and the stored-value smart-card. While the IUs were produced specifically for the ERP system, the smart-cards were marketed by a consortium of local banks for multiple uses.

The second group comprises equipment installed in the field - at the ERP gantries. These include the antennae, the vehicle detectors and the enforcement camera system. Data collected is transmitted back to the Control Centre continuously through leased telecommunication lines.

The third group of components is at the Control Centre, and includes various back-end computers, monitoring systems as well as a master-clock to ensure that the timing at all the ERP gantries are synchronised. All the financial transactions and violation images are processed here.

The ERP system is designed to be simple to use. With the smart-card inserted into the IU, the appropriate ERP charge would be automatically deducted whenever the vehicle passes through the ERP gantry. There would be a short beep to signify a successful transaction. Should there be insufficient cash in the smart-card or should there be no smart-card in the $\mathrm{IU}$, the enforcement cameras in the gantry will take a picture of the rear of the vehicle. A similar enforcement picture would also be taken of any vehicle that had no IU installed. The vehicles' registration numbers would be automatically read using OCR techniques and the vehicles' owners issued with letters asking for payments of outstanding charges, inclusive of administrative fees. Failure to pay the charges and fees could result in the offender being called up to appear in the Courts.

3. GPS-based technology for road pricing was not available at that time, and hence the systems considered at that time was based on the use of electronic transponders that could be each encoded with its own unique identifier code. Even then, the transponders available then required vehicles to be travelling in a single queue, while the requirements we have was for a free-flowing multi-lane solution. Three contractors were short-listed and their solutions tried on newly-completed and unopened stretches of roads. The Government provided funding of $\mathbf{S} \$ 1$ million to each of the 3 contractors to mitigate their risks and cover part of their expenses. The transponder or IU was designed to deduct congestion charges directly from inserted smartcards, primarily to deal with the issue of privacy since transaction records need not be kept by any central computer system; it had only to be stored in the inserted smartcard. 


\section{PRE-ERP LAUNCH PROGRAMMES}

There were two major programmes launched prior to the start of the ERP. The first was the installation of IUs on the then 680,000 eligible vehicles while the second was on publicity, to get motorists and motorcyclists aware and ready for the ERP system.

The publicity programme was an important element in making the launch of the ERP a success. It started even before the start of the IU fitting programme and was in place for more than a year, all the way up to and beyond the launch date of the ERP system. All vehicle owners were sent brochures, detailing the ERP system, how it works and the differences between that and the then working ALS/RPS. Advertisements were also placed in the print media as well as on television to drum up awareness of the new road pricing system.

\section{AFFECTED VEHICLES AND CHARGES}

With the ERP system, all vehicles are required to have IUs fitted if they intend to pass through the ERP gantries. ERP charges are applicable for all types of vehicles during the operating hours, with the exception of emergency vehicles (ambulances, fire engines and police cars). The charges vary from $\$ 0.50$ to $\$ 3.00$ per passage through the ERP gantries when the system was first launched.

\section{TRAFFIC IMPACT}

Traffic volume into the CBD had reduced by about $10-15 \%$ during the ERP operation hours, when compared to the ALS scheme. While the charge payable by most motorists was lower, ranging from $\$ 0.50$ to $\$ 2.50$, as compared to the ALS, there was one major change in the pricing structure that brought about a change in travel behaviour. There was no longer the unlimited number of entries into the CBD with the ERP system for a single payment. It was estimated that about $23 \%$ of trips that entered the CBD during the ALS days were repeat trips, i.e. whose marginal road pricing charge was zero. Hence, with ERP, many of these multiple trip-makers cut down their number of trips, e.g. office workers no longer use their 
cars to attend mid-day meetings or lunches - more relied on the public transport system instead.

\section{Varying the Road Pricing Charge}

The ERP system, being less dependent on manpower, allowed more frequent changes to be made to the road pricing charges. This helped to better optimise usage of road space in the network. The rates are set to ensure that flow rate are kept as high as is practicable (and thereby allowing the maximum number of road users to benefit), and this is measured using average speeds as the proxy. On urban roads, the average speeds should be between 20 $\mathrm{km} / \mathrm{h}$ to $30 \mathrm{~km} / \mathrm{h}$ while that for expressways, the speeds should be between $45 \mathrm{~km} / \mathrm{hr}$ to 65 $\mathrm{km} / \mathrm{hr}^{4}$. When speed goes above the upper threshold, too few vehicles are deemed to be using the roads and hence, the road space available is not being optimally used. Hence, the road pricing charge can be reduced to allow more vehicles to use the roads. Conversely, if the speed falls below the lower threshold, too many vehicles are on the roads and this is a signal that the road pricing charge can be increased.

This ERP rate review is conducted every 3 months, and over the years, the rates have stabilized with only a handful of gantries having their rates adjusted each time the ERP rate review takes place.

\section{The Economics of Singapore's ERP System}

The original ERP contract was worth about $\$ \$ 200 \mathrm{mil}$, with half the amount being for a million IUs. There were originally 33 ERP gantries, but this has now expanded to 66. The cost of each IU including installation was $\mathbf{S} \$ 150$, but for the 680,000 existing vehicle owners at that time, this cost was borne by the Government.

Given that the ERP scheme charges for each passage through the ERP gantries, it was expected at that time that motorists would be paying more than what they had collectively been doing so under the ALS. Hence, the annual road-tax structure was reviewed to have each motorist paying lower road taxes. In addition, there was a one-off road tax rebate for each vehicle owner, so that overall the introduction of the ERP would be revenue-neutral to the Government. This was also to make the ERP scheme more palatable to the motoring public.

Although the ERP revenue collected goes to the Government Consolidated Fund and not hypothecated for transport, much effort was made to stress that the ERP system is a traffic management tool and not for revenue collection. As it turned out, the revenue collected when the ERP scheme started operations turned out to be significantly lower than what was

4. The computation of these optimum speed ranges are based on speed-flow curves derived from empirical data collected on expressways and arterial roads. The lower speed threshold is a value close to the optimum point of the speed-flow curves that gives the maximum traffic flow. On expressways, this is $45 \mathrm{~km} / \mathrm{hr}$ and on arterial roads, this is $20 \mathrm{~km} / \mathrm{hr}$. The lower value for arterial roads is due to the presence of traffic signals and side-friction caused by various road-side activities such as on-street parking and the picking up or dropping off of passengers. The upper speed thresholds were chosen to allow stability in the ERP rates, as too narrow a range is likely to give oscillating ERP rates each time that they are reviewed. 
collected with the $\mathrm{ALS}^{5}$, about $30 \%$ lower. However, given that the ERP system is a traffic management tool, this lower-than-anticipated ERP revenue collection was not an issue. With the increased number of gantries, revenue has naturally increased and presently is marginally more than what was collected under the ALS. Given that revenue was not the reason for ERP, there were no explicit cost-benefit assessments, although there was much effort to contain the costs of implementing and operating the system. Instead, it relied on the outcome in terms of observed travel speeds on the roads to gauge the effectiveness of the ERP.

Naturally, the cost of each ERP gantry has increased over the years and presently, each typical ERP gantry costs about 11/2 times than of what it was in 1998. While the cost of each IU has also increased, the installation costs have come down due to the various installers having more experience and having sunk in their overheads. Hence, the cost of installing an IU today has remained the same as what it was before, at S\$150 for each IU including installation. The cost of managing and maintaining the ERP system has increased over the years, consistent with the increase in the number of gantries and IU numbers, but this has remained about $20-30 \%$ of total revenue collected.

\section{Extending the Coverage of ERP}

With the launch of the ERP in 1998, transport planners started to investigate its use to manage congestion outside the city. An Outer Cordon that charges motorists passing through it was planned, but it was decided that each of these roads entering the Outer Cordon would only have ERP gantries implemented when travel speeds on each of these roads fall below the threshold. Hence, the Outer Cordon gantries were introduced gradually, starting from 1999. As at end 2008, 15 ERP gantries of a total 21 needed to complete the Outer Cordon are in use to manage traffic during the peak periods.

\section{ERP to Manage Home-Based Trips}

The ERP gantries that replaced the ALS, and the subsequent ones on the Outer Cordon had been effective in managing traffic flows into the city. However, these ERP gantries do not affect traffic flows flowing out of the city, and consequently some of the major corridors taking traffic away from the city towards major residential areas became congested. Hence, the pricing strategy had to be extended to deal with home-bound trips during the evening peak period. In Aug 2005, an ERP gantry was introduced on a major expressway leading from the city to the north, at its most congested stretch. Traffic re-distributed to other roads and other time periods, with traffic volume dropping by around $25 \%$ initially on this major expressway during the evening peak period from 6 to 8 pm on weekdays.

However, over time the traffic came back onto the expressway, and a significant portion of the traffic actually left the expressway just before the gantry. This behaviour meant the on this expressway, upstream of the ERP gantry, congestion became prevalent. Hence, two years later in Nov 2007, another ERP gantry had to be introduced upstream of the existing one. Based on the traffic flow profile on this expressway, this new ERP gantry has to operate from 5:30pm to 10:30pm on weekdays. Traffic volume on this stretch of expressway reduced by about $20 \%$ during this 5 -hour period, and congestion cleared up.

5. About $\$ \$ 100$ mil a year was collected with the ALS, just before it was fully replaced with the ERP system in Sep 1998. 


\section{ERP to Manage Intra-City Traffic in the Shopping Belt}

The CBD pricing cordon covers a part of the city that is predominately shopping in nature, and had traffic characteristics somewhat different from the office-based city roads. This is the Orchard Road shopping belt and since most of the shops opened after 10:30am, there was low traffic flow there during the morning peak period. However, from mid-day onwards, heavy traffic with recurring congestion was normal, on both weekdays and on Saturdays.

About $35 \%$ of the traffic on the main shopping thoroughfare was found to be through traffic i.e. going beyond the shopping area and to the office-dominant area in the CBD.

Hence, the ERP scheme for this area was refined in 2005, with the shopping belt made into a sub-zone with additional gantries at its boundary with the office-dominant CBD area (see figure 1). These new gantries allow three pricing strategy changes to respond to the traffic flows in the shopping belt.

First, the ERP charges for traffic going into this shopping zone during the morning peak period were removed since there was no congestion there at that time of the day. Second, from mid-day onwards, the ERP charge for traffic going through the shopping sub-zone into the office-dominant area had to go through 2 ERP gantries and the total charge was set to be higher than that for going into the office-dominant area directly via other roads. This cut down the amount of through traffic on these shopping streets, reducing from about $35 \%$ to $20 \%$. To ensure that this change was not to discourage shopping trips, the ERP charge for those destined for the shops was actually reduced. As a result, the volume of destination traffic remained unchanged. Third, the shopping sub-area was now priced on Saturdays without having the office-dominant area (which had no congestion on weekends) to be charged as well.

Figure 1: Separating the shopping belt from

the office-dominant area

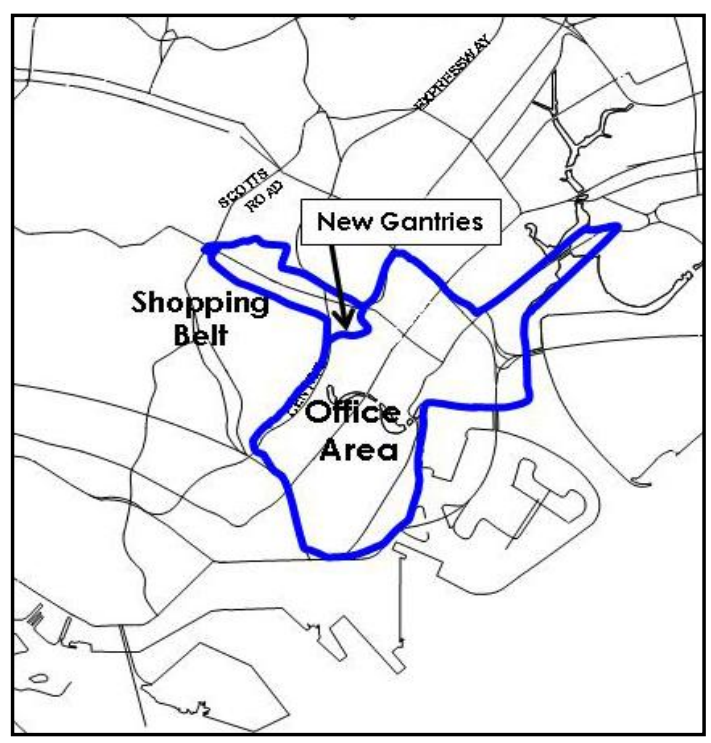


The outcome of this pricing strategy change was in line with expectations. Hourly traffic on the shopping streets was reduced by $14-36 \%$ during the priced periods on weekdays and reduced by $19-34 \%$ on Saturdays, and this came predominately from a reduction in through traffic. Indeed, a survey of vehicles entering the car-parks in the shopping area showed a slight increase on both weekdays and Saturdays. In addition, the car-parks there on Sundays also showed increased usage. One can argued that the pricing strategy change has influence some of the weekday/ Saturday shoppers to do their shopping on Sundays, and the relief of traffic congestion on weekdays/Saturdays have attracted new shopping traffic into that area.

\section{ERP to Manage Intra-City Traffic during the Evening Peak}

With increasing traffic in the city, the pricing strategy was revised to deal with intra-city traffic in 2008 because the then-ERP scheme does not impose any charges on vehicles travelling solely within the city roads.

The office-dominant CBD was divided into 2 parts with a new pricing line along the Singapore River involving just 5 ERP gantries. Traffic crossing this line in either direction was subjected to ERP charges (see figure 2) but this was only during the evening peak period from $6-8 p m$, since it was only during this time that congestion was severe enough. Following this change in pricing strategy, the hourly traffic going across the city passing this line dropped by between $28-37 \%$ during the evening peak period. This was a significant drop in traffic and there were concerns from the shopping community which had also saw a drop in their businesses.

Figure 2: Managing intra-city traffic congestion with a new pricing line

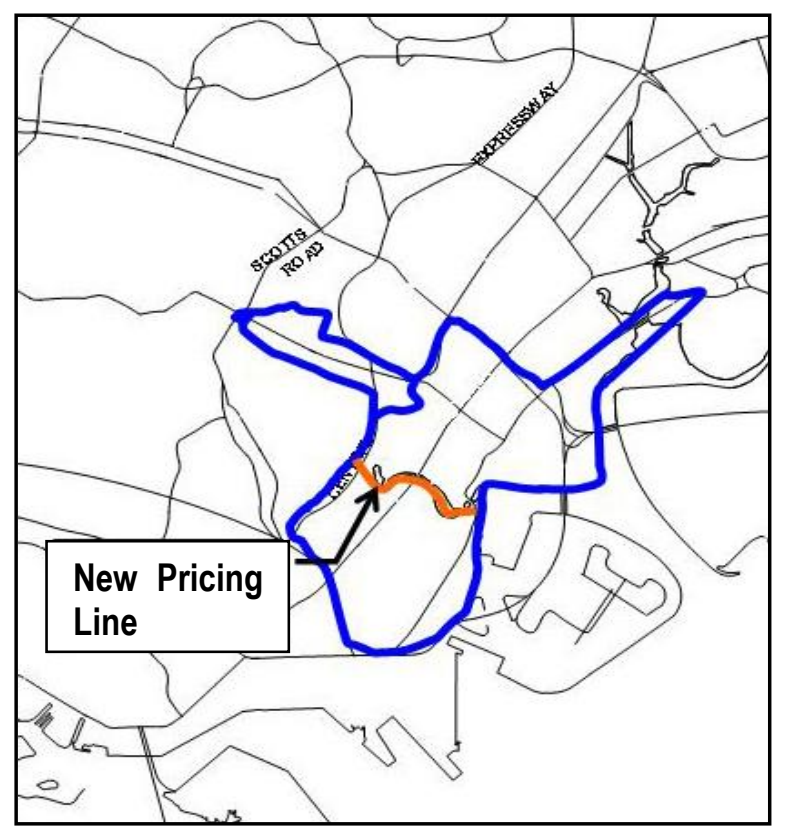


However, it was not conclusive that this drop in business was a direct result of the pricing strategy change because there was also a decline in the general economic activity brought about by the worldwide financial difficulties. Nevertheless, given that the travel speeds on the roads were increased significantly, there was an adjustment in the ERP rates 3 months later, in line with the established pricing adjustment criterion. The net reduction thereafter in traffic flow became smaller as expected following this pricing adjustment, with the reduction in hourly traffic now by up to $30 \%$ (instead of $37 \%$ ), in relation to traffic conditions before the introduction of the new pricing line. Traffic conditions on the city roads remained relatively good.

\section{OTHER ISSUES}

Road pricing schemes and the issue of privacy are never separable. Hence, there was much done to allay the fears of motorists. Being an active system, there was no necessity for the central computer system to keep track of vehicle movements since all charges were deducted from the inserted smart-card at the point of use. Records of such transactions were kept in the memory chip of the smart-card that belonged to the individual. The authorities also took a further step to assure the public that all records of transactions required to secure payments from the banks were erased from the central computer system once this was done - typically within 24 hours.

The issue of the ERP system as a revenue tool for the Government was also raised. However, ERP has always been positioned as a traffic management tool and revenue was and is never a consideration. Indeed, when the ERP system replaced the ALS in 1998, the revenue collected was only about $60 \%$ of what it used to be. Nevertheless, there had to be a continued effort to publicise that ERP is not a revenue-generating tool, and to drive home this point, there were reduction in vehicle up-front taxes and recurring annual licence fees whenever there were major changes in the ERP scheme.

\section{LESSONS LEARNT}

One of the major lessons learnt from Singapore's experience must be the importance of being flexible and adaptive, and be ready to make changes to the congestion pricing schemes to target specific groups contributing to traffic congestion on the roads e.g. the Orchard Cordon to deal with shopping traffic and the New Pricing Line that passes through the city to manage intra-city traffic.

The rationale for congestion pricing should be robust and supported by real-life experiences of the motorists as they travel on the roads. In Singapore, travel speeds experienced on the 
roads under the influence of the ERP pricing gantries are used to decide on the introduction of ERP, and to the adjustment of the rates. The provisions to made adjustments to the rates 6 times a year to deal with changing and seasonal traffic patterns, when it occurs, is useful to convince motorists that the road pricing scheme is a traffic management tool and not a revenue-generating one. Ultimately, the scheme should be technically and logically robust. It should also be kept simple, so as to allow all users to understand easily the reasons why and how the road pricing schemes work.

While a congestion pricing scheme may be justified from a technical perspective and can be rationally argued for, utmost importance must be given to communicating the rationale of the scheme to road-users and the communities including the businesses. There is always never too much communications and publicity when it comes to road pricing schemes. In Singapore's case, even with intense publicity and communications, there are still instances where motorists would claim ignorance or continue to challenge the validity of the scheme.

There should always be viable alternatives for motorists who decide not to pay the congestion pricing charges - it might be an alternate route or alternate time of travel. For those who decide not to drive, there has to be a viable public transport alternative. In the latest revisions to the ERP pricing strategies in 2008, significant effort was expanded to increase public transport capacity, with premier buses (private buses offering seated bus services almost from door-to-door during peak periods), reduced headways on public buses and on the underground trains and expanded bus lanes \& bus priority schemes.

In addition, congestion pricing schemes should not be seen as a means to increase revenue for the Government. There should be corresponding reduction in taxes or expenditures by the vehicle users, which should be equal or greater than the expected collections from the road pricing scheme. In the recent road pricing changes made in 2008 , vehicle taxes were reduced by about $\$ 110$ million per year, and this was much higher than the expected $\$ 70$ million increase in ERP pricing revenue. The challenge is to have the motoring public retain this information on the reduction in vehicle taxes as a beneficial trade-off for them, as unlike the ERP charges which are recurring almost on a daily basis, this reduction in vehicle taxes is either a once-off occurrence (at time of purchase of the vehicle) or annual or semi-annual (road tax is payable once a year or once every six months).

Congestion pricing schemes are not the ultimate solutions to traffic congestion in urban areas. Ultimately, it has to be a combination of schemes. Travel demand has to be managed also in other ways e.g. through proper land-use planning and de-centralisation policies, parking policies, car-ownership policies (in Singapore, this is the Vehicle Quota Scheme) and an increasingly more effective (public) transport alternative. Road network capacity must still be improved but perhaps more selectively, and technology used to continuously optimise the available capacity. These includes appropriate resources to deal with obstructions caused by accidents and traffic incidents on the road network, as delays in clearing these obstructions will only mean more congested roads in the network, with or without congestion pricing. 


\section{CONCLUSION}

Since congestion pricing was introduced to manage traffic on Singapore's roads in 1975, there was a recognised need that the pricing strategies to keep traffic flowing have to be continually evolved to meet changing traffic conditions. The pricing strategies have also to be sensitive to specific needs of the community, be it the shops or the offices. Over the past 35 years, Singapore has been refining and making changes to the pricing strategies to meet the changing circumstances but the principle of congestion pricing as a traffic management tool to tackle traffic congestion has remained unchanged. 


\section{REFERENCES}

Menon, A P G \& Chin, Kian-Keong (1998) - The Making of Singapore's Electronic Road Pricing System - Proceedings of the International Conference on Transportation into the next Millennium, Singapore

Menon, A P G \& Chin, Kian-Keong (2004) - ERP in Singapore - what's been learnt from five years of operation? - Traffic Engineering \& Control (tec), Vol 45 No. 2, Feb 2004.

$\mathrm{Li}$, Michael Z.F. (2002) - The role of speed-flow relationship in congestion pricing implementation with an application to Singapore - Transportation Research Part B 36 (2002)

Chin, Kian-Keong (2005) - Road Pricing - Singapore's 30 Years of Experience - CESifo DICE Report, Journal for Institutional Comparisons, Vol 3, No.3 Autumn 2005

Harun, Halim, Chin, Kian Keong, Leong, Wai Yan (2009) - Managing Traffic on City Roads: A Demand Management Approach $-2^{\text {nd }}$ World Roads Conference, Singapore 
